\title{
MODY probability calculator for GCK and HNFIA screening in a multiethnic background population
}

Roberta Magalhães Tarantino ${ }^{1}$

https://orcid.org/0000-0001-7759-1564

Gabriella de Medeiros Abreu²

https://orcid.org/0000-0002-0434-3815

Ana Carolina Proença de Fonseca ${ }^{2}$

https://orcid.org/0000-0001-6123-0481

Rosane Kupfer ${ }^{3}$

https://orcid. org/0000-0002-4073-0038

Maria de Fátima Carvalho Pereira ${ }^{4}$

https://orcid. org/0000-0003-3932-6481

Mario Campos Júnior ${ }^{2}$

https://orcid.org/0000-0002-7121-0748

Lenita Zajdenverg

https://orcid. org/0000-0002-1579-3299

Melanie Rodacki'

https://orcid.org/0000-0002-9007-1325

\begin{abstract}
Objective: We aimed to identify the frequency of monogenic diabetes, which is poorly studied in multiethnic populations, due to GCK or HNF1A mutations in patients with suggestive clinical characteristics from the Brazilian population, as well as investigate if the MODY probability calculator (MPC) could help patients with their selection. Subjects and methods: Inclusion criteria were patients with DM diagnosed before 35 years; body mass index $<30 \mathrm{~kg} / \mathrm{m}^{2}$; negative autoantibodies; and family history of DM in two or more generations. We sequenced HNF1A in 27 patients and GCK in seven subjects with asymptomatic mild fasting hyperglycemia. In addition, we calculated MODY probability with MPC. Results: We identified 11 mutations in 34 patients (32.3\%). We found three novel mutations. In the GCK group, six cases had mutations $(85.7 \%)$, and their MODY probability on MPC was higher than $50 \%$. In the HNF1A group, five of 27 individuals had mutations (18.5\%). The MPC was higher than $75 \%$ in 11 subjects (including all five cases with HNF1A mutations). Conclusion: Approximately one third of the studied patients have GCK or HNF1A mutations. Inclusion criteria included efficiency in detecting patients with GCK mutations but not for HNF1A mutations $(<20 \%)$. MPC was helpful in narrowing the number of candidates for HNF1A screening. Arch Endocrinol Metab. 2020;64(1):17-23
\end{abstract}

\section{Keywords}

GCK; HNF1A; MODY; monogenic diabetes

\author{
${ }^{1}$ Seção de Diabetes e Nutrologia, \\ Departamento de Medicina \\ Interna, Universidade Federal \\ do Rio de Janeiro (UFRJ), \\ Rio de Janeiro, RJ, Brasil \\ ${ }^{2}$ Laboratório de Genética \\ Humana, Instituto Oswaldo \\ Cruz, Fundação Oswaldo Cruz, \\ Rio de Janeiro, RJ, Brasil \\ ${ }^{3}$ Seção de Diabetes, Instituto \\ Estadual de Diabetes e \\ Endocrinologia do Rio de Janeiro, \\ Rio de Janeiro, RJ, Brasil \\ ${ }^{4}$ Departamento de Patologia Clínica \\ da Universidade Federal do Rio de \\ Janeiro, Rio de Janeiro, RJ, Brasil
}

Correspondence to:

Roberta M. Tarantino

Rua Rodolpho Paulo Rocco, 255,

Ilha do Fundão

21941-590 - Rio de Janeiro, RJ, Brasil drarobertatarantino@gmail.com

Received on Feb/25/2019

Accepted on Jun/19/2019

DOI: 10.20945/2359-3997000000173

\section{INTRODUCTION}

$\mathrm{T}$ he frequency of monogenic diabetes mellitus (DM) has been underestimated in various populations (1). Most cases are caused by mutations in GCK [glucokinase gene] (GCK MODY [maturity onset diabetes of the young]) or HNFIA [hepatocyte nuclear factor l-alpha gene] (HNFlA MODY) (2). Their molecular diagnosis is expensive but promotes the improvement of genetic counseling and treatment (3). Strategies to select the ideal subjects to screen for monogenic DM (MDM) in different populations are necessary to establish cost-effective diagnostic algorithms.
Different authors have developed clinical criteria for MODY screening based on age, family history and clinical characteristics $(4,5)$. Although their use appears to be cost-effective (6), there is a concern that the screening based on clinical criteria would either miss part of the affected patients or still result in an excessive number of genetic tests (7). Therefore, authors have pursued optimal strategies for selecting patients. Shields and cols. developed a clinical prediction model that generates a probability of MODY (8) and shows good discrimination between MDM and type I (TIDM) or type $2 \mathrm{DM}$ (T2DM) in European patients diagnosed under 35 years. The performance of this calculator in non-Caucasians is unknown. 
The Brazilian population is very diverse and comprises individuals from multiple ethnic backgrounds, especially Caucasoid and Afro-descendants. There are scarce data about the prevalence of MDM and its optimal screening strategy in this setting. Our aim in this study was to estimate the frequency of MDM due to GCK or HNFIA mutations in patients with suggestive clinical characteristics and to investigate if the MODY probability calculator (MPC) could improve patient detection in this population $(8,9)$.

\section{SUBJECTS AND METHODS}

In this cross-sectional observational study, we selected patients clinically defined with monogenic diabetes from two specialized centers in Rio de Janeiro, between March 2012 and June 2015. MODY screening is not part of the routine laboratory panel of either center. We analyzed thirty-four unrelated probands from Brazilian families for mutations in GCK and HNFIA.

The inclusion criteria were age of DM diagnosis $\leq$ 35 years, body mass index $(\mathrm{BMI}) \leq 30 \mathrm{~kg} / \mathrm{m}^{2}$ or 95 th percentile at onset, negative anti-glutamic decarboxylase antibody (anti-GAD) and anti-islet antigen 2 antibody (anti-IA2) antibodies and family history of diabetes in at least two generations, excluding the generation of the index case, and/or two or more first-degree relatives at the same side of the family. We excluded patients with TIDM; past diabetic ketoacidosis; clinical signs of insulin resistance (acanthosis nigricans, increased abdominal circumference and obesity); and secondary causes of diabetes.

The Ethics and Research Committee of the Clementino Fraga Filho University Hospital and State institute of Diabetes and Endocrinology of Rio de Janeiro approved this study protocol. We informed all participants about the aim of this study and provided verbal and written consent.

We calculated the positive predictive value (PPV) for MODY based on the MPC for each patient (8) and divided the patients into two groups. The GCK group included patients with fasting hyperglycemia (100-154 $\mathrm{mg} / \mathrm{dL})$; increased glycaemia after $75 \mathrm{~g}$ anhydrous dextrose $<54 \mathrm{mg} / \mathrm{dL}$ and HbAlc $<7.5 \%$ (58 mmol/ $\mathrm{mol}$ ); and evolutionarily stable disease (even without antidiabetic drugs), most often asymptomatic and with hyperglycemia since birth (10). The HNFIA group included all other cases that met the inclusion criteria and that did not have the profile for the GCK group.
We isolated genomic DNA from peripheral blood leukocytes using QIAamp DNA Blood Mini Kit (Qiagen, Hilden, Germany). Also, we purified PCR products using Clean Sweep PCR Purification Reagent (Applied Biosystems, Vilnius, Lithuania). Then, we performed screening of the entire coding sequence of GCK and HNFIA genes through bidirectional Sanger sequencing using the Big Dye Terminator Kit v3.1 (Applied Biosystems, Austin, TX, USA), conducted on an ABI 3130 Automatic Genetic Analyzer (Applied Biosystems). Primers sequences are available upon request. We confirmed all mutations by bidirectional sequencing of a second PCR reaction. Then, we estimated the serum levels of anti-GAD and anti-IA2 antibodies by means of an enzyme-linked immunosorbent assay method (ELISA) using a EUROIMMUN kit.

We checked the variants identified against public Databases PubMed, Clinvar, dbSNP (https://www. ncbi.nlm.nih.gov/), Human Genome Mutation Database (HGMD $\left.{ }^{\circledR}\right)$ (http://www.hgmd.cf.ac.uk/ ac/), ExAC Browser (http://exac.broadinstitute. org), GnomAD (http://gnomad.broadinstitute. org/) and 1000 Genomes project database (http:// www.internationalgenome.org/) to investigate their previous identification in the literature. We performed functional analyses using Mutation Taster (http:// www.mutationtaster.org) (11-13).

We evaluated the differences between patients with mutations and others with Student's t-test and chi-square tests. In addition, we performed statistical analysis using SPSS software (version 22.0).

\section{RESULTS}

\section{Characteristics of the study group}

We included 34 individuals $(61.7 \%$ females $)$ with a mean age of DM diagnosis and a duration of 19.8 \pm 8.8 and $14.6 \pm 9.9$ years, respectively, as well as a mean BMI of $22.8 \pm 3.2 \mathrm{~kg} / \mathrm{m}^{2} .55 .8 \%$ used insulin, and $41.2 \%$ used oral antidiabetic drugs (OAD). Their previous DM classifications included the following: non-classified in $38.2 \%$, T1DM in $35.3 \%$, T2DM in $23.5 \%$ and gestational diabetes (GDM) in 3\%. Patients in the GCK $(\mathrm{n}=7)$ and HNFIA $(\mathrm{n}=27)$ groups had similar age at onset $(16.1 \pm 7.8$ vs $20.8 \pm 9.0$ years; $\mathrm{p}=$ $0.286)$, diabetes duration $(9.88 .8$ vs $15.4 \pm 10.1$ years; $\mathrm{p}=0.82)$ or BMI $(20.6 \pm 4.0$ vs $23.3 \pm 2.8 ; \mathrm{p}=0.143)$.

None of the patients in the GCK group used insulin, and one used OAD. Most patients (70.3\%) in 
the $H N F A$ group used insulin (mean dose: $0.9 \pm 0.4$ $\mathrm{UI} / \mathrm{kg} /$ day), and $48.1 \%$ used OAD.

\section{Genetic tests}

We found MODY mutations (GCK or HNFIA) in 11 patients $(32.3 \%)$. Fifty per cent of patients with nonclassified DM had mutations in GCK or HNFIA. We fond mutations in $16.6 \%$ of those previously classified as TIDM and in none classified as T2DM. The only patient classified as GDM had a GCK mutation.

In the GCK-suspicious group, six cases had mutations $(85.7 \%)$ : Five were missense mutations: p.Tyr6lAsp (c.181T>G; novel); p.Arg191Trp (c.571C>T); p.Thr228Met (c.683C $>$ T); p.Ala384Val (c.1151C>T); p.Gly227Asp (c.680G $>$ A); and one in-frame deletion p.Phel50del (c.449_451delTCT). We tested the patient in this group without the $G C K$ mutation for HNFIA, and we found no mutations.

In the MODY-HNFIA-suspicious group, we found five mutations (5/27-18.5\%); three missense substitutions: p.Gly31Asp (c.92G>A), p.Vall33Glu (c.398T >A; novel) and p.Trpl65Arg (c.493T>C); one nonsense mutation: p.Arg171Ter $(c .511 \mathrm{C}>\mathrm{T})$; and one frameshift insertion: p.Thr433Hisfs ${ }^{*} 116$ (c.1296_1297insC; (novel). Patients with HNFIA mutations used insulin less frequently than others. Those who used insulin reported a lower insulin dose $/ \mathrm{kg}$ (Table 1). Other characteristics of those with or without HNFIA mutations are shown in Table 1.

Among the 11 mutations, eight had already been described, and three were novel mutations. The mutation p.Tyr6lAsp $($ c.181T>G), found in exon 2 of the GCK gene of one patient, is a missense mutation classified as pathogenic. The other two novel mutations occurred in the HNFIA gene (exons 2 and 6). We considered the missense mutation p.Vall33Glu (c.398T>A) and the frameshift insertion p.Thr433Hisfs*116 (c.1296_1297insC) pathogenic because they alter the codon reading frame due to the insertion of a nucleotide (Table 2).

Table 1. Clinical characteristics of patients according to mutations in the HNF1A gene

\begin{tabular}{|c|c|c|c|}
\hline & \multicolumn{2}{|c|}{ Mutation } & \multirow{2}{*}{ p } \\
\hline & Present $(n=5)$ & Absent $(n=22)$ & \\
\hline \multicolumn{4}{|l|}{ Sex } \\
\hline Female & $1(20 \%)$ & $15(68.2 \%)$ & 0.048 \\
\hline Male & $4(80 \%)$ & $7(31.8 \%)$ & \\
\hline Age of diagnosis (years) & $17.6 \pm 6.8$ & $21.5 \pm 9.4$ & 0.237 \\
\hline $\mathrm{BM}^{*}\left(\mathrm{~kg} / \mathrm{m}^{2}\right)$ & $22.08 \pm 3.73$ & $23.6 \pm 2.6$ & 0.154 \\
\hline Insulin use & $1(20 \%)$ & $18(81.8 \%)$ & 0.006 \\
\hline$O A D^{\star \star}$ use & $3(60 \%)$ & $10(45.4 \%)$ & 0.557 \\
\hline \multicolumn{4}{|l|}{ Affected generations } \\
\hline 1 & 0 & $5(22.7 \%)$ & 0.054 \\
\hline 2 or more & $5(100 \%)$ & $17(77.3 \%)$ & \\
\hline \multicolumn{4}{|l|}{ Age of diagnosis/grade } \\
\hline Childhood & 0 & $3(13.6 \%)$ & 0.323 \\
\hline Adolescence & $3(60 \%)$ & $6(27.3 \%)$ & \\
\hline Adult & $2(40 \%)$ & $13(59.1 \%)$ & \\
\hline Diabetes presentation & & & 0.583 \\
\hline Insidious & $1(20 \%)$ & $3(13.6 \%)$ & \\
\hline Abrupt ${ }^{\#}$ & $4(80 \%)$ & 19 (82.6\%) & \\
\hline Diabetes Duration (years) & $8.6 \pm 7.06$ & $16.95 \pm 10.13$ & 0.432 \\
\hline MODY probability (PPV) & $75.5 \pm 0.0$ & $35.7 \pm 30.9$ & $<0.001$ \\
\hline Mean insulin dose per kg of weight (units/kg) & 0.37 & $0.9 \pm 0.37$ & - \\
\hline
\end{tabular}

Note: Quantitative variables are presented as mean and standard deviation. Categorical variables are presented as total number (n) and percentage (\%). The age groups used included the following: childhood, 0-9 years, adolescence, 10-19 years and adult, over 20 years (17).

* BMI: body mass index; ${ }^{\star \star}$ OAD: oral anti diabetic drug; * Symptoms of insulinopenia such as polyuria, polydipsia and weight loss. 
Table 2. Mutations identified in this study

\begin{tabular}{|c|c|c|c|c|c|c|c|c|c|c|c|}
\hline Gene & Exon & Patient & $\begin{array}{l}\text { Change in } \\
\text { protein }\end{array}$ & Change in DNA & Consequence & $\begin{array}{c}\text { SIFT } \\
\text { prediction }\end{array}$ & $\begin{array}{l}\text { SIFT } \\
\text { score }\end{array}$ & Polyphen & $\begin{array}{l}\text { Mutation Taster } \\
\text { prob. }\end{array}$ & ClinVar & Reference \\
\hline \multirow[t]{6}{*}{ GCK } & 2 & P40 & p.Tyr61Asp & c. $181 \mathrm{~T}>\mathrm{G}$ & Missense & Deleterious & 0 & $\begin{array}{l}\text { Probably } \\
\text { harmful }\end{array}$ & 0.999999998323156 & NA & $\begin{array}{c}\text { This study, } \\
\text { novel }\end{array}$ \\
\hline & 4 & P1 & p.Phe150del & c.449_451delTCT & $\begin{array}{l}\text { In-frame } \\
\text { deletion }\end{array}$ & NA & NA & NA & 0.9999999999980624 & NA & $\begin{array}{l}\text { Massa and } \\
\text { cols., } 2001\end{array}$ \\
\hline & 5 & P7 & p.Arg191Trp & c. $571 \mathrm{C}>\mathrm{T}$ & Missense & Deleterious & 0 & $\begin{array}{l}\text { Probably } \\
\text { harmful }\end{array}$ & 0.999999947468603 & Pathogenic & $\begin{array}{l}\text { Ellard and } \\
\text { cols., } 2000\end{array}$ \\
\hline & 7 & P29 & p.Gly227Asp & c. $680 \mathrm{G}>\mathrm{A}$ & Missense & Deleterious & 0 & $\begin{array}{l}\text { Probably } \\
\text { damaging }\end{array}$ & 0.999999999998095 & NA & $\begin{array}{l}\text { Domínguez- } \\
\text { López and } \\
\text { cols., } 2013\end{array}$ \\
\hline & 7 & P9 & p.Thr228Met & c. $683 \mathrm{C}>\mathrm{T}$ & Missense & Deleterious & 0 & $\begin{array}{l}\text { Possibly } \\
\text { harmful }\end{array}$ & 0.99999999999911 & Pathogenic & $\begin{array}{l}\text { Stoffel and } \\
\text { cols., } 1992\end{array}$ \\
\hline & 9 & P32 & p.Ala384Val & c. $1151 \mathrm{C}>\mathrm{T}$ & Missense & Tolerated & 0.06 & $\begin{array}{l}\text { Possibly } \\
\text { harmful }\end{array}$ & 0.999999998673333 & $\begin{array}{l}\text { Uncertain } \\
\text { meaning }\end{array}$ & $\begin{array}{l}\text { Costantini } \\
\text { and cols., } \\
2014\end{array}$ \\
\hline \multirow[t]{5}{*}{ HNF1A } & 1 & P4 & p.Gly31Asp & c. $92 \mathrm{G}>\mathrm{A}$ & Missense & Tolerated & 0.29 & $\begin{array}{l}\text { Possibly } \\
\text { harmful }\end{array}$ & 0.995035768629034 & Pathogenic & $\begin{array}{l}\text { Chèvre and } \\
\text { cols., } 1998\end{array}$ \\
\hline & 2 & P28 & p.Val133Glu & c.398T>A & Missense & Deleterious & 0 & $\begin{array}{l}\text { Possibly } \\
\text { harmful }\end{array}$ & 0.999999999738075 & NA & $\begin{array}{c}\text { This study, } \\
\text { novel }\end{array}$ \\
\hline & 2 & P13 & p.Trp165Arg & c. $493 \mathrm{~T}>\mathrm{C}$ & Missense & Deleterious & 0 & $\begin{array}{l}\text { Possibly } \\
\text { harmful }\end{array}$ & 0.999999998737327 & NA & $\begin{array}{l}\text { Tatsi and } \\
\text { cols., } 2013\end{array}$ \\
\hline & 2 & P37 & p.Arg171Ter & c. $.511 \mathrm{C}>\mathrm{T}$ & Nonsense & NA & NA & NA & 1 & Pathogenic & $\begin{array}{c}\text { Vaxillaire } \\
\text { and cols., } \\
1999\end{array}$ \\
\hline & 6 & P5 & p.Thr433Hisfs*116 & C.1296_1297insC & $\begin{array}{l}\text { Frameshift- } \\
\text { insertion }\end{array}$ & NA & NA & NA & 1 & NA & $\begin{array}{c}\text { This study, } \\
\text { novel }\end{array}$ \\
\hline
\end{tabular}

NA: not applicable; prob: probability of causing disease.

We recruited the family of all three probands with novel mutations, as presented in the pedigrees (Figure 1). We recruited four family members of the patient with the p.Tyr6lAsp mutation in GCK. Then, we tested all four individuals with diabetes. The brother and sister had the same p.Tyr6lAsp mutation, and we observed that it was inherited from the mother with diabetes. The father with recent onset DM (after 50 years of age) did not have the mutation. We recruited the mother with DM of the patient with the mutation p.Thr433Hisfs*116. She also had the same mutation. Four family members of the patient (three sisters and the mother) with the mutation p.Vall33Glu in HNFIA were recruited. The only sister with diabetes also had the same mutation of the patient, and they inherited the mutation from their healthy mother. We believe it may be a case of incomplete penetrance uncommon with HNFIA mutations but already observed by other authors $(14,15)$. In addition, the mutation p.Vall33Glu was absent in the two healthy sisters.

\section{MODY probability calculator}

In the sample as a whole, $61.8 \%$ of patients $(n=21)$ had PPV > 50\%, and 50\% $(\mathrm{n}=17)$ had $\mathrm{PPV}>75 \%$, according to the MPC. In those with PPV > 50\%, $47.6 \%$ had mutations, and in those with PPV > 75\%, $52.9 \%$ had mutations.

\section{HNF1A group}

The probability of MODY, according to MPC, was $\geq$ $50 \%$ in 14 patients $(51.8 \%)$ and $\geq 75 \%$ in 11 patients (40.7\%). All five patients in the HNFIA group with mutations had PPV for MODY $\geq 75 \%$ (Table 1 ). We found a mutation in 5/11 (45\%) patients with PPV $\geq 75 \%$ and in $5 / 14(35.71 \%)$ of those with PPV $\geq 50 \%$.

\section{GCK group}

Six patients had PPV $\geq 75 \%$, and 1 had PPV between 50 and $75 \%$. We detected GCK mutations in 5 patients with PPV $\geq 75 \%$ and in patients with PPV between 50 and $75 \%$, but not in 1 individual with PPV $\geq 75 \%$.

\section{DISCUSSION}

In this study, we identified patients with phenotypes suggestive of MDM and performed mutation screening for GCK and HNFIA genes. We found mutations in $32.3 \%$. 

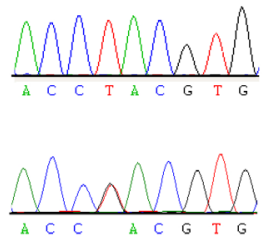

II

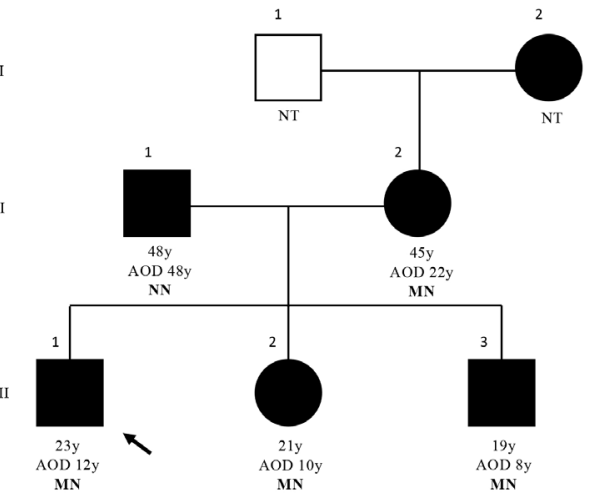

B

Family 5

HNF1A p.Thr433Hisfs*116 (c.1296_1297insC)
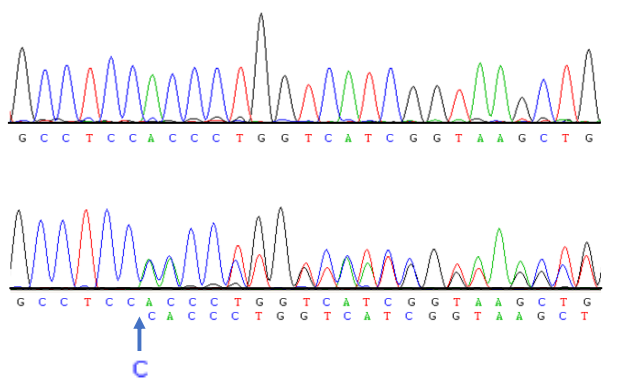

II

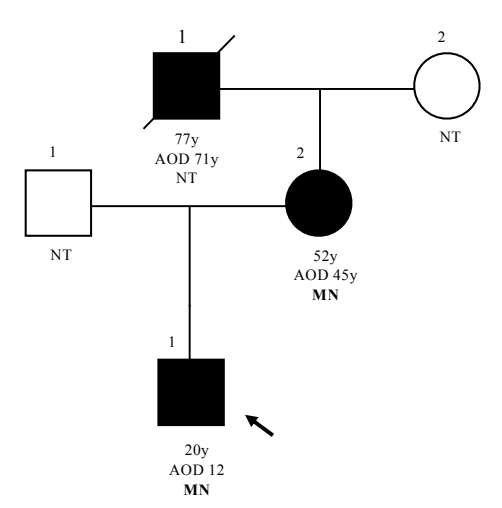

C

Family 28

HNF1A p.Val133Glu (c.398T >A)
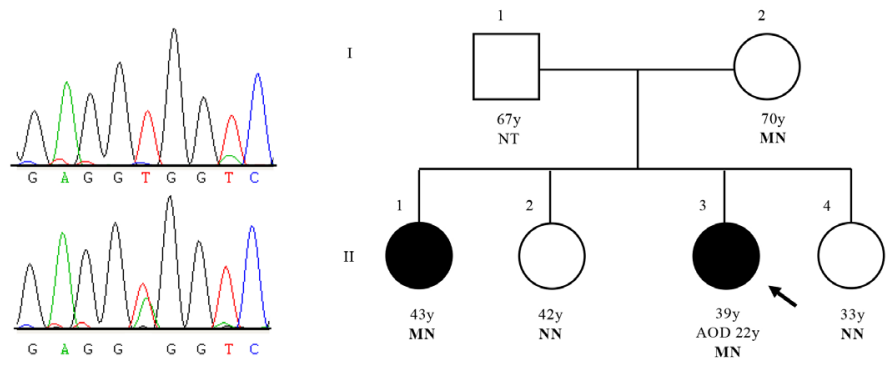

Figure 1. Pedigree and genotype of novel mutations. (A) Family 40 with the GCKp.Tyr61Asp (c.181T>G) in heterozygous state. K: allele T or G. (B) Family 5 showing the novel insertion HNF1A p.Thr433Hisfs*116 (c.1296_1297insC). The blue arrow indicates where the insertion occurs. (C) Family 28 presenting the HNF1A p.Val133Glu (c.398T>A). W: allele T or A. Filled symbols and empty symbols represent subjects with diabetes and healthy individuals, respectively. The present age of the individuals is show below the symbols in years, followed by age of diagnosis (AOD) in years and genotype interpretation. Genotypes are expressed by normal allele $(\mathrm{N})$ and mutated allele $(\mathrm{M})$; NT: Not tested. An arrow indicates the index case. 
Although a high frequency of mutations in these two genes have been reported in individuals with a clinical diagnosis of MDM from several populations, especially from Northern Europe (16,17), others (including Southern Europeans, Asians and Brazilians) have found a lower frequency of mutations, as true with our findings (18-21). In some populations, other types of diabetes might share clinical features with MDM more frequently than others. Alternatively, other genes implicated in the pathogenesis of MODY could be more frequent in these groups, such as $H N F 4 A$, insulin promoter factor-1 (IPF-1), HNF1B, NeuroDl and others. In the other two studies with Brazilian cohorts $(20,21)$, approximately $60 \%$ of patients with clinical suspicion of MDM did not have mutations in HNFIA, GCK or HNF4A genes, but we did not test other MODY genes.

In those with mild fasting hyperglycemia, we found GCK mutations in $85.7 \%$, which suggests a high sensitivity for the clinical criteria. The frequency of GCK mutations in this study was slightly higher than previously reported for most populations (42.4 to 61\%), including Brazilians (21-23). We found mutations in HNF1A, the most common gene for non-GCK MDM, in $18.5 \%$, which was much like the data obtained by Santana and coworkers in the Brazilian population but lower than reported in other populations (16-19,24). Therefore, the clinical criteria for the selection of patients for GCK testing seem to be adequate in most populations, including ours. Surprisingly, we found the opposite for non-GCK MODY. This suggests that an improvement in the clinical criteria to adequately select patients for screening is necessary or that, alternatively, other genes should also be investigated.

We have evaluated if MPC (8) could help identify a group of patients that would be more suitable for screening. All patients with HNFIA mutations had $\mathrm{PPV}>75 \%$. If we had selected only subjects above this cutoff, $60 \%$ of the patients would not have been tested. This strategy would make the screening more cost-effective. However, the frequency of mutations in other genes in patients with a clinical diagnosis of nonGCK MODY is still not known for our population. It is possible that patients without HNFIA mutations could have alterations in other MODY genes, which would be overlooked with this strategy.

In this study, a cutoff for MODY probability of $>75 \%$ and $>62 \%$, based on MPC, was found in all patients with HNFIA and GCK mutations, respectively. Although in UK the current pick-up rate for MODY testing is PPV $>25 \%(9)$, other authors have found a good specificity and negative predictive value in higher cutoff values (> 62.5\%) for detecting MODY in nonCaucasian population (25). Our findings suggest that higher cutoff values should be considered for MODY screening in non-Caucasian populations.

This study has some limitations. First, we included a limited number of patients. Secondly, we tested only two MODY genes for financial reasons. Additionally, we used only one methodology (Sanger sequencing) to investigate mutations. This method is unable to detect copy number variations, large deletions and duplications that can represent up to $3 \%$ of all genetic alterations of the GCK, HNFIA and HNF4A (26). Another concern is related to the absence of a control group. The selection of the studied population was done in a pragmatic way when the patient did not present clinical criteria of T1 or T2 DM. An additional potential limitation is the lack of C-peptide measurement as a screening tool for MODY. The strengths of our study included finding three novel mutations not previously reported and providing new information about the screening of monogenic diabetes in individuals with multiethnic backgrounds. For future studies, we aim to bypass these limitations and to perform functional genomic studies to confirm novel mutations as pathogenic ones.

In conclusion, we investigated MODY mutations in patients with clinical features suggestive of MDM from a multiethnic background. Approximately one third of patients with clinical features suggestive of MDM from a multiethnic background had GCK or HNFIA mutations. While clinical criteria were efficient for detecting patients with GCK mutations, we found HNFIA mutations in less than $20 \%$ of the cases. Although MPC has not been validated for nonCaucasians, its use as a screening tool for selecting patients to test for $H N F 1 A$ mutations, using a cutoff of $75 \%$, would reduce the number of tests in $60 \%$ and increase the percentage of positive cases to $45 \%$. These data suggest that the use of the MPC could be a costeffective strategy for selecting patients to screening for non-GCK MODY mutations, but it is important to consider the possible role of non-HNFIA mutations in non-Caucasian populations such as ours.

Acknowledgements: professor Tânia Maria Ruffoni Ortiga, from the Laboratory of Translational Endocrinology of the Biophysics Institute Carlos Chagas Filho, and professor Márcia Mattos Gonçalves Pimentel, head of the Human Genetics Service of State University of Rio de Janeiro, who assisted in the initial phases of the research. 
Contributions: RMT was the physician responsible for recruiting patients in the study, gathering and analyzing the data and writing the manuscript. GMA was responsible for the molecular genetics and bioinformatic analysis. ACPF contributed to statistical analysis of the data. RK reviewed the manuscript. FC reviewed the manuscript. MC reviewed and edited the manuscript. LZ contributed to the discussion. MR reviewed and edited the manuscript and contributed to the discussion. The authors are grateful to the patients and their families, as well as to all the authors who approved the final version of this article.

Funding: this work was supported by National Council for Scientific and Technological Development (CNPq) and Oswaldo Cruz Institute (IOC).

Disclosure: RMT has been a Novo Nordisk employee (i.e., regional medical advisor) since July 2017 but started the monogenic diabetes research project in 2012 and judges that it could not inappropriately influence (bias) this work. The other authors have no declarations of interest.

\section{REFERENCES}

1. Kropff J, Selwood MP, McCarthy MI, Farmer AJ, Owen KR. Prevalence of monogenic diabetes in young adults: a communitybased, cross-sectional study in Oxfordshire, UK. Diabetologia. 2011;54(5):1261-3.

2. Ellard S, Bellanne-Chantelot C, Hattersley AT; European Molecular Genetics Quality Network (EMON) MODY group. Best practice guidelines for the molecular genetic diagnosis of maturity-onset diabetes of the young. Diabetologia. 2008;51(4):546-53.

3. Van der Zwaag AM, Weinreich SS, Bosma AR, Rigter T, Losekoot $M$, Henneman $L$, et al. Current and best practices of genetic testing for maturity onset diabetes of the young: views of professional experts. Public Health Genomics 2015;18(1):52-9.

4. Tattersall RB. Mild familial diabetes with dominant inheritance. $\mathrm{Q}$ J Med. 1974;43(170):339-57.

5. Thanabalasingham G, Owen KR. Diagnosis and management of maturity onset diabetes of the young (MODY). BMJ. 2011;343:d6044.

6. Naylor RN, John PM, Winn AN, Carmody D, Greeley SA, Philipson $\mathrm{LH}$, et al. Cost-effectiveness of MODY genetic testing: translating genomic advances into practical health applications. Diabetes Care. 2014;37(1):202-9.

7. Shields BM, Hicks S, Shepherd MH, Colclough K, Hattersley AT, Ellard S. Maturity-onset diabetes of the young (MODY): how many cases are we missing? Diabetologia. 2010;53(12):2504-8.

8. Shields BM, McDonald TJ, Ellard S, Campbell MJ, Hyde C, Hattersley AT. The development and validation of a clinical prediction model to determine the probability of MODY in patients with young-onset diabetes. Diabetologia. 2012;55(5):1265-72.

9. Murphy R, Ellard S, Hattersley AT. Clinical implications of a molecular genetic classification of monogenic beta-cell diabetes. Nat Clin Pract Endocrinol Metab. 2008;4(4):200-13.

10. McDonaldTJ, Ellard S. Maturity onset diabetes of the young: identification and diagnosis. Ann Clin Biochem. 2013;50(Pt 5):403-15.

11. Ng PC, Henikoff S. SIFT: Predicting amino acid changes that affect protein function. Nucleic Acids Res. 2003;31(13):3812-4.
12. Sunyaev S, Ramensky V, Koch I, Lathe W 3rd, Kondrashov AS, Bork P. Prediction of deleterious human alleles. Hum Mol Genet. 2001;10(6):591-7.

13. Schwarz JM, Cooper DN, Schuelke M, Seelow D. MutationTaster2: mutation prediction for the deep-sequencing age. Nat Methods. 2014;11(4):361-2.

14. Hansen T, Eiberg H, Rouard M, Vaxillaire M, MØller AM, Rasmussen SK, et al. Novel MODY3 mutations in the hepatocyte nuclear factor-1alpha gene: evidence for a hyperexcitability of pancreatic beta-cells to intravenous secretagogues in a glucose-tolerant carrier of a P447L mutation. Diabetes. 1997;46(4):726-30.

15. Elbein SC, Teng K, Yount P, Scroggin E. Linkage and molecular scanning analyses of MODY3/hepatocyte nuclear factor-1 alpha gene in typical familial type 2 diabetes: evidence for novel mutations in exons 8 and 10. J Clin Endocrinol Metab. 1998;83(6):2059-65.

16. Frayling TM, Bulamn MP, Ellard S, Appleton M, Dronsfield MJ, Mackie AD, et al. Mutations in the hepatocyte nuclear factor-1alpha gene are a common cause of maturity-onset diabetes of the young in the U.K. Diabetes. 1997;46(4):720-5.

17. Estalella I, Rica I, Perez de Nanclares G, Bilbao JR, Vazquez JA, San Pedro Jl, et al.; Spanish MODY Group. Mutations in GCK and HNF-1alpha explain the majority of cases with clinical diagnosis of MODY in Spain. Clin Endocrinol (Oxf). 2007;67(4):538-46

18. Johansen A, Ek J, Mortensen HB, Pedersen O, Hansen T. Half of clinically defined maturity-onset diabetes of the young patients in Denmark do not have mutations in HNF4A, GCK, andTCF1. J Clin Endocrinol Metab. 2005;90(8):4607-14.

19. Kyithar MP, Bacon S, Pannu KK, Rizvi SR, Colclough K, Ellard S, et al. Identification of HNF1A-MODY and HNF4A-MODY in Irish families: phenotypic characteristics and therapeutic implications. Diabetes Metab. 2011;37(6):512-9.

20. Moises RS, Reis AF, Morel V, Chacra AR, Dib SA, Bellanne-Chantelot $\mathrm{C}$, et al. Prevalence of maturity-onset diabetes of the young mutations in Brazilian families with autosomal-dominant earlyonset type 2 diabetes. Diabetes Care. 2001;24(4):786-8.

21. 21.Santana LS, Caetano LA, Costa-Riquetto AD, Quedas EPS, Nery $M$, Collett-Solberg $P$, et al. Clinical application of ACMGAMP guidelines in HNF1A and GCK variants in a cohort of MODY families. Clin Genet. 2017;92(4):388-96.

22. Carmody D, Naylor RN, Bell CD, Berry S, Montgomery JT, Tadie EC, et al. GCK-MODY in the US National Monogenic Diabetes Registry: frequently misdiagnosed and unnecessarily treated. Acta Diabetol. 2016;53(5):703-8.

23. Capuano M, Garcia-Herrero CM, Tinto N, Carluccio C, Capobianco V, Coto I, et al. Glucokinase (GCK) mutations and their characterization in MODY2 children of southern Italy. PLoS One. 2012;7(6):e38906.

24. Giuffrida FMA, Moises RS, Weinert LS, Calliari LE, Manna TD, Dotto RP, et al on behalf of the Brazilian Monogenic Diabetes Study Group (BRASMOD). Maturity-onset diabetes of the young (MODY) in Brazil: Establishment of a national registry and appraisal of available genetic and clinical data. Diabetes Res and Clin Pract. 2017;123:134-42.

25. Ang SF, Lim SC, Tan CSh, Fong JC, Kon WY, Lian JX, Subramanium T, Sum CF. A preliminary study to evaluate the strategy of combining clinical criteria and next generation sequencing (NGS) for the identification of monogenic diabetes among multi-ethnic Asians. Diabetes Res Clin Pract. 2016;119:13-22.

26. Ellard S, Thomas K, Edghill EL, Owens M, Ambye L, Cropper J, et al. Partial and whole gene deletion mutations of the GCK and HNF1A genes in maturity-onset diabetes of the young. Diabetologia. 2007;50(11):2313-7. 